\title{
EZ-DripLoss Assessment in Chicken Breast Meat Using Different Sample Areas, Fiber Orientation, and Measurement Intervals
}

\author{
Ana Kaić ${ }^{1, *}$, Zlatko Janječić ${ }^{2}\left(D\right.$, Andrija Žanetić ${ }^{1}$, Nikolina Kelava Ugarković ${ }^{1} \oplus$ and Klemen Potočnik ${ }^{3}$ \\ 1 Department of Animal Science and Technology, University of Zagreb Faculty of Agriculture, \\ Svetošimunska Cesta 25, 10002 Zagreb, Croatia; andrija.7595@hotmail.com (A.Ž.); nkelava@agr.hr (N.K.U.) \\ 2 Department of Animal Nutrition, University of Zagreb Faculty of Agriculture, Svetošimunska Cesta 25, \\ 10002 Zagreb, Croatia; zjanjecic@agr.hr \\ 3 Department of Animal Science, Biotechnical Faculty, University of Ljubljana, Groblje 3, \\ SI-1230 Domžale, Slovenia; klemen.potocnik@bf.uni-lj.si \\ * Correspondence: akaic@agr.hr
}

check for updates

Citation: Kaić, A.; Janječić, Z.; Žanetić, A.; Kelava Ugarković, N.; Potočnik, K. EZ-DripLoss Assessment in Chicken Breast Meat Using Different Sample Areas, Fiber Orientation, and Measurement Intervals. Animals 2021, 11, 1095. https://doi.org/10.3390/ani11041095

Academic Editors: John

Michael Gonzalez and Casey M. Owens

Received: 1 March 2021

Accepted: 8 April 2021

Published: 12 April 2021

Publisher's Note: MDPI stays neutral with regard to jurisdictional claims in published maps and institutional affiliations.

Copyright: (c) 2021 by the authors. Licensee MDPI, Basel, Switzerland. This article is an open access article distributed under the terms and conditions of the Creative Commons Attribution (CC BY) license (https:// creativecommons.org/licenses/by/ $4.0 /)$.
Simple Summary: Drip loss is one of the most important parameters of meat quality evaluation. A new method for the determination of drip loss in poultry meat is the EZ-DripLoss method. The results of the drip loss method used are highly dependent on the surface area, its weight, the fiber direction of the sample, and the storage period. From the literature reports it is obvious that there is a deficiency in our knowledge of the EZ-DripLoss method's suitability for poultry meat analysis. Therefore, this study aimed to research the effect of different sample core diameters (10, 20, and $30 \mathrm{~mm}$ ), and fiber orientations (vertical vs. horizontal) on the EZ-DripLoss in chicken breast meat measured across a period of five days. The results indicate that the EZ-DripLoss for chicken breast meat is highly dependent on the sample area, fiber orientation, and measurement interval. Although the EZDripLoss method is considered to be simple and reproducible, it is still insufficiently researched and standardized. Comparison of the EZ-DripLoss results obtained with different sampling procedures should be performed with great precaution.

Abstract: Although the EZ-DripLoss method has been performed in numerous studies, there is a deficiency in our knowledge of the EZ-DripLoss method's suitability for poultry meat analysis. This study aimed to research the effect of different sample areas $(10,20$, and $30 \mathrm{~mm} ; n=240)$, and fiber orientations (vertical vs. horizontal) on the EZ-DripLoss in chicken breast meat measured across a period of five days. The influence of sample area on the EZ-DripLoss of chicken breast meat with respect to the fiber orientation and across the five-day measurement interval was significant between 10 and $30 \mathrm{~mm}$ samples, and between 20 and $30 \mathrm{~mm}$ samples $(p<0.001)$. The estimated regression coefficient showed that EZ-DripLoss for the samples with horizontal and vertical fiber direction of 10 and $20 \mathrm{~mm}$, significantly increased by $0.04 \%$ per hour, while for the samples with vertical fiber direction whose diameter was $30 \mathrm{~mm}$, it significantly increased by $0.06 \%$ per hour, and for the horizontal fiber direction, it significantly increased by $0.07 \%$ per hour. The samples with vertical fiber orientation had $0.50 \%$ greater EZ-DripLoss compared to the samples with horizontal fiber orientation. EZ-DripLoss evaluation in chicken breast should be performed with a sample core diameter of $20 \mathrm{~mm}$, a vertical fiber orientation, and over the course of longer measurement intervals.

Keywords: core diameter; holding time; meat quality; myofibril direction; poultry; water-holding capacity

\section{Introduction}

The quality of poultry meat relates largely to its water-holding capacity (WHC) which is associated with processing technology and consumer acceptance. WHC in the form of excessive dripping from meat and meat products can represent a significant loss of weight 
from carcasses and cuts and may affect the yield and quality of processed meats, as well as being unattractive for consumers [1]. It has been proven that drip loss, as a measure of WHC, is one of the most important parameters of meat quality evaluation [2]. The amount of excessive drip loss affects both qualitative and quantitative aspects of a muscle, while the industry requires methods that can easily, and with a great precision, determine the WHC of meat and meat products [2].

The two most widely utilized gravimetric methods for measuring drip loss are the bag method, recognized internationally as the standard method, and the relatively new, but widely used in the industry, EZ-DripLoss method [3]. The EZ-DripLoss method was suggested by Rassmussen and Anderson [4] and is described in detail in the "Instruction manual for EZ-DripLoss" [5]. In brief, EZ-DripLoss is a method in which the meat is left suspended in a specialized EZ airtight container for a $24 \mathrm{~h}$-long period to drip, with gravity as the only force exerted on the meat. Abundant research has reported that the EZ-DripLoss method has greater sensitivity, is easier to perform in a reproducible way, and uses less space than other conventional methods [2,6-8]. However, it must be taken into consideration that in relation to the well-standardized bag method, there is a broad diversity in procedures related to the EZ-DripLoss method.

According to the "Instruction manual for EZ-DripLoss" [5], drip loss is evaluated after a $1 \mathrm{~d}$ measurement interval, and the sample core fiber orientation is vertical. With porcine meat, Otto et al. [9] and Filho et al. [2] recommended using a $2 \mathrm{~d}$ measurement interval and a $45^{\circ}$ fiber orientation for accuracy with the EZ-DripLoss method. Kilgannon et al. [10] suggested a $3 \mathrm{~d}$ measurement interval as 'best practice' to determine drip loss when using the EZ-DripLoss method for beef. Holman et al. [11] reported that fiber orientation (vertical vs. horizontal) did not affect EZ-DripLoss, and that longer measurement intervals (more than $4 \mathrm{~d}$ ) are recommended for lamb meat. In addition to inconsistencies of used methodology, it is well known that the results of used drip loss methods are highly dependent on the area sampled, its weight, the fiber direction of the sample, and the storage period $[2,11,12]$. Furthermore, from the literature reports, it is obvious that there is a deficiency in our knowledge of the EZ-DripLoss method's suitability for poultry meat analysis. Regarding the aforementioned, this study aimed to research the effect of different sample core diameters (Ø 10, 20, and $30 \mathrm{~mm}$ ), and fiber orientations (vertical vs. horizontal) on the EZ-DripLoss in chicken breast meat measured across a period of five days.

\section{Materials and Methods}

The study was conducted in accordance with Croatian legislation (Animal Protection Act, Official Gazette 102/17; Regulation on the Protection of Animals Used for Scientific Purposes, Official Gazette 55/13), and was approved by the Bioethical Committee for the Protection and Welfare of Animals at the University of Zagreb, Faculty of Agriculture, Croatia (Class: 114-04/20-03/10; Ref. 251-71-29-02/19-20-2, 30-11-2020).

\subsection{Animals and Muscle Sampling}

A total of 40 chicken broilers from the line Ross 308 were used in the study. The animals were slaughtered at $35 \mathrm{~d}$ of age. After the slaughtering procedure and evisceration process, the carcasses were chilled at $4{ }^{\circ} \mathrm{C}$ for $24 \mathrm{~h}$ in a cold chamber.

The samples for the analysis were taken in the laboratory from the pectoralis muscle (PM) of each carcass at $24 \mathrm{~h}$ post-mortem. Chicken breast meat was manually trimmed of skin, visible fat, and connective tissue. In detail, two slices (diameter $30 \mathrm{~mm}$; height $35 \mathrm{~mm}$ ) were removed from the cranial side of the PM. From each cranial end of the slice, three cylindrical muscle cores were removed (from the lateral to the medial side) using EZ-DripLoss circular knives. The muscle cores were removed following the fiber orientation (being horizontal or vertical in relation to the circular knife), and having a 10, 20 , and $30 \mathrm{~mm}$ diameter. Each individual meat sample $(n=240)$ was weighed, placed in a special EZ container (Danish Meat Research Institute, Taastrup, Denmark), and stored in a refrigerator at an average temperature of $+3.5^{\circ} \mathrm{C}( \pm 0.80$ s.d.). Sample cores were reweighed 
at daily intervals over a period of five days (in total: five measurement intervals). Drip loss assessment was performed after the aforementioned measurement intervals based on the change in sample weight, and was expressed as a percentage. Before each final weighing, the muscle surface samples were dabbed.

\subsection{Statistical Analyses}

Data was analyzed using the SAS/STAT software package version 9.4 [13]. Basic statistic parameters for EZ-DripLoss were calculated using the MEANS procedure, while the analysis of variance was performed by using MIXED procedures. The following mixed model was applied for the analysis of each type of fiber orientation (vertical vs. horizontal) of EZ-DripLoss:

$$
y_{i j k}=C_{i}+b_{i}\left(x_{i j k}\right)+s_{j}+e_{i j k}
$$

where: $y_{i j k}$-dependent variable, $C_{i}$-fixed effect of core diameter $(i=10,20$, and $30 \mathrm{~mm}$ ), $b_{i}$-interaction of linear regression coefficient with effect of core diameter, $x_{i j k}$-independent variable hour, $s_{j}$-random effect of sample $(j=1,2,3, \ldots, 40)$, and $e_{i j k}$-random residual. For graphical interpretation of regression curves and confidential limits, the PLM procedure was used. To assess the difference between vertical and horizontal fiber orientations, they were included as a fixed effect in the aforementioned mixed model. Post hoc comparison among the least square means between fiber orientations (vertical vs. horizontal) and core diameters $(10,20$, and $30 \mathrm{~mm})$ was performed using a Bonferroni multiple test correction. The differences were considered to be significant if $p<0.05$.

\section{Results and Discussion}

First of all, it is necessary to present that the fitted models had a high explanatory and predictive ability of the EZ-DripLoss in reference to fiber orientation. Prediction of EZ-DripLoss by using vertical fiber orientation provided the overall coefficient of determination $\left(R^{2}\right)$ of 0.82 , whereas for horizontal fiber orientation $R^{2}$ was 0.87 .

\subsection{The Influence of Sample Area on the EZ-DripLoss}

The influence of the area sampled on the EZ-DripLoss of chicken breast meat with respect to the vertical and horizontal fiber orientation and the measurement interval of 24, $48,72,96$, and $120 \mathrm{~h}$ was statistically significant between samples with a diameter of 10 and $30 \mathrm{~mm}$, and a diameter of 20 and $30 \mathrm{~mm}(p<0.001$; Figures 1 and 2$)$.

Differences between estimated linear regression coefficients of the EZ-DripLoss between samples with a diameter of 10 and $30 \mathrm{~mm}$ can be attributed to manipulative procedures when sampling, i.e., excluding samples of $10 \mathrm{~mm}$ with circular knife, and excluding samples of $30 \mathrm{~mm}$ from the containers prior to weighing. In addition, Holman et al. [11] pointed out that smaller samples also had a lower retention force, i.e., immobilization of retained water, which means that they displayed significantly more drip loss. With alpaca meat, Logan et al. [8] reported significant differences in drip loss determined by the bag method between samples of different weights. The authors found a drip loss of $4.04 \%$ in samples weighing $80 \mathrm{~g}$, and $3.38 \%$ in samples weighing $60 \mathrm{~g}$.

\subsection{The Influence of Fiber Orientation on EZ-DripLoss}

Of particular interest was the influence of the fiber orientation on the EZ-DripLoss of chicken breast meat. The results indicate that the fiber orientation significantly affects the EZ-DripLoss in chicken breast meat $(p<0.0001)$. It was found that the samples with vertical fiber orientation had a $0.50 \%$ greater drip loss compared to the samples with horizontal fiber orientation. This difference could be attributed to structural elements in muscle where 'free water' expelled from meat as drip loss is associated with vertical fiber direction and its movement in vertical samples is accelerated due to the greater gravimetric forces [2,11]. With lamb meat, however, Holman et al. [11] did not find a statistically significant difference in drip loss between the samples with vertical and horizontal fiber orientation during measurements at four $24 \mathrm{~h}$ intervals $(24,48,72$, and $96 \mathrm{~h})$. 


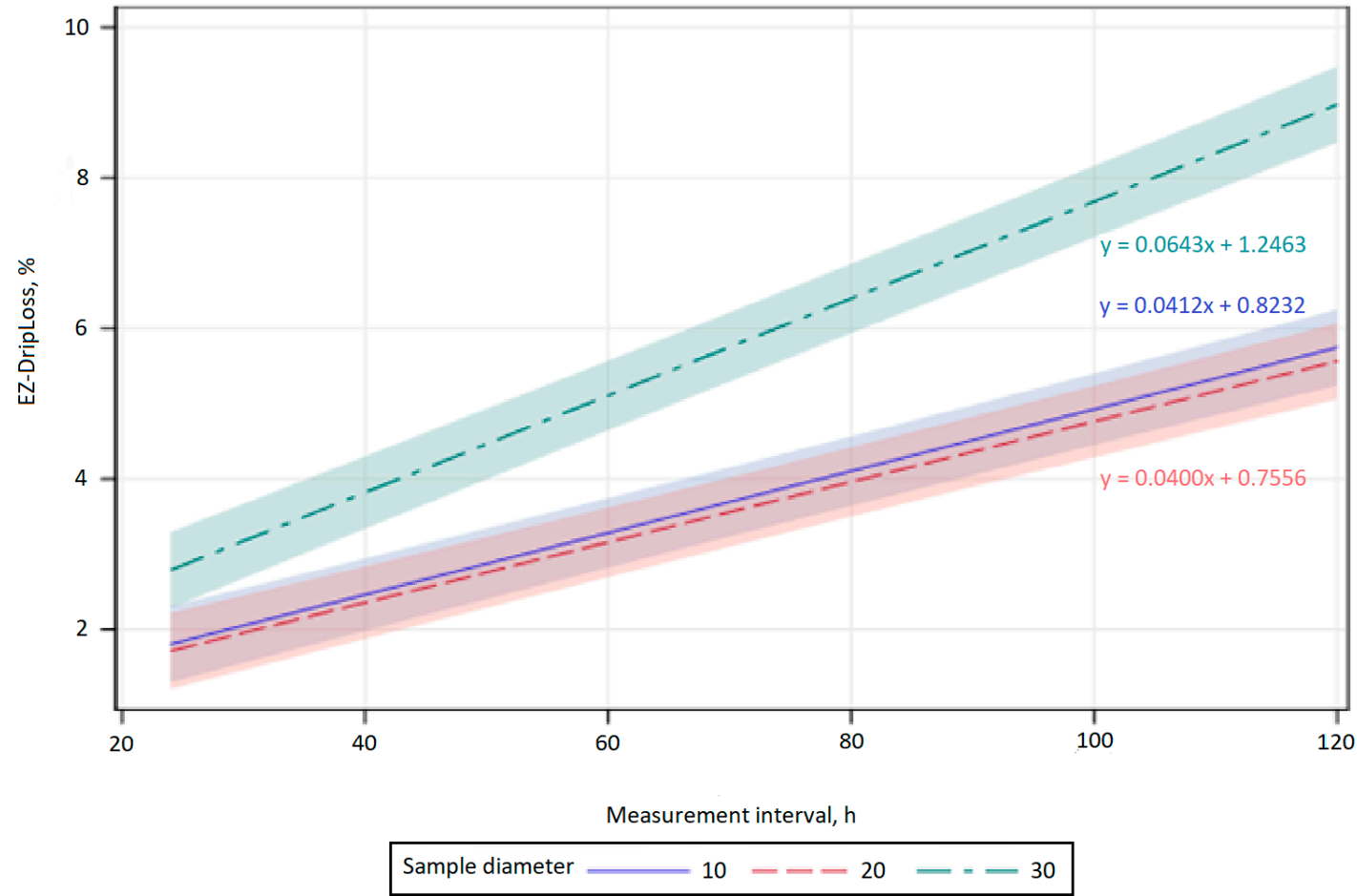

Figure 1. Predictions and confidence bands for a linear regression of measurement interval for EZ-DripLoss of chicken breast meat in relation to vertical fiber direction and core diameter $(10,20$, and $30 \mathrm{~mm})$.

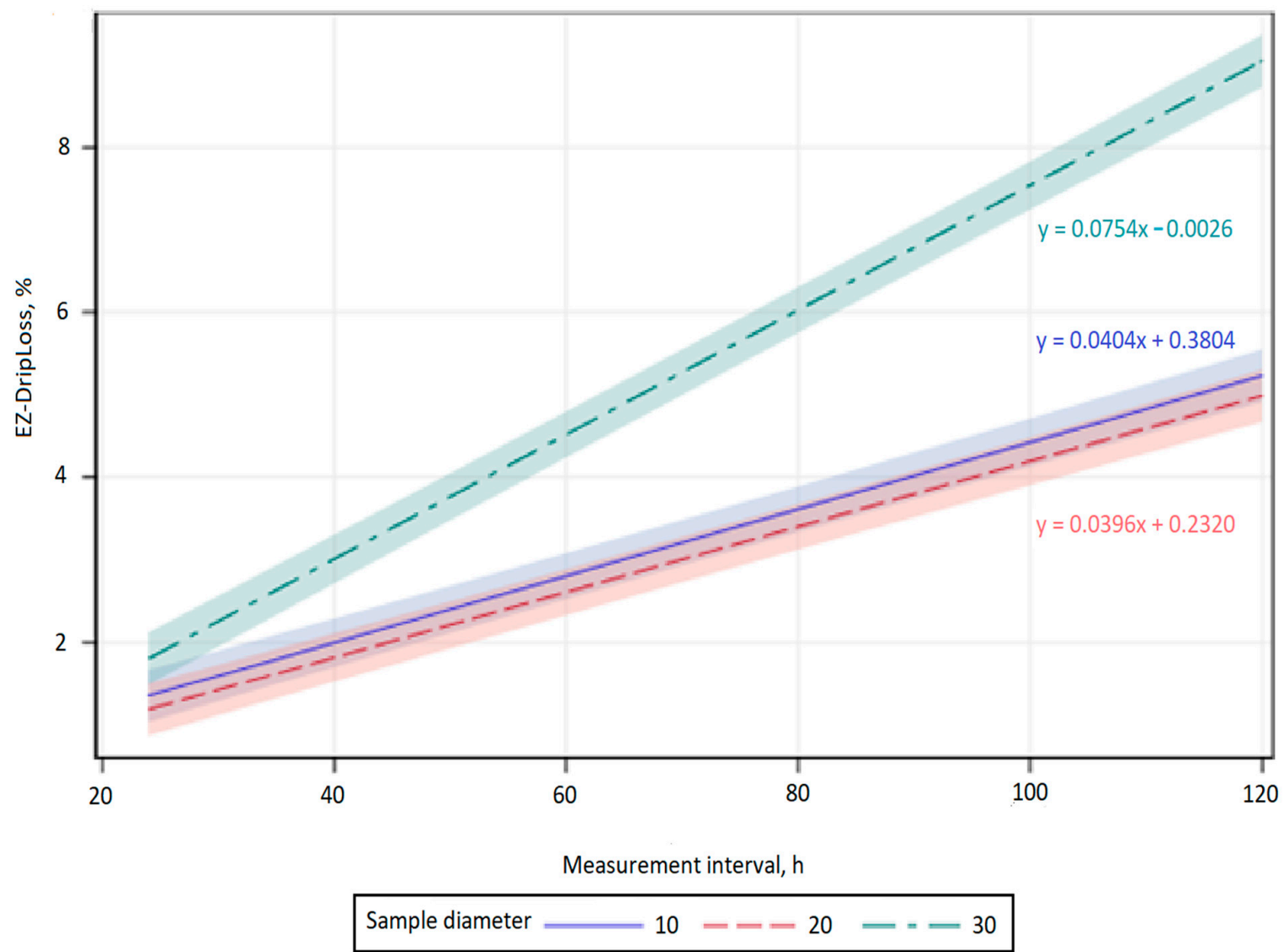

Figure 2. Predictions and confidence bands for a linear regression of measurement interval for EZ-DripLoss of chicken breast meat in relation to horizontal fiber direction and core diameter $(10,20$, and $30 \mathrm{~mm})$. 


\subsection{The Influence of Measurement Interval on EZ-DripLoss}

The results of the present study indicate a significant and positive linear increase in EZ-DripLoss for the samples with horizontal and vertical fiber direction whose diameter was 10, 20, and $30 \mathrm{~mm}$ during all investigated measurement intervals $(p<0.001$; Figures 1 and 2). The estimated regression coefficient showed that drip loss for the samples with horizontal and vertical fiber direction whose diameter was 10 and $20 \mathrm{~mm}$, significantly increased by $0.04 \%$ per hour. In addition, the estimated regression coefficient also showed that drip loss for the samples with vertical fiber direction whose diameter was $30 \mathrm{~mm}$, significantly increased by $0.06 \%$ per hour, and for the horizontal fiber direction, significantly increased by $0.07 \%$ per hour. As already mentioned, an increase in drip loss over time is expected, as exudation is known to be a slow process that lasts for days, during which water expelled from the myofibrils accumulates in the muscle [14]. The results of the present study (Tables 1 and 2) are in accordance with previous studies using the EZ-DripLoss method [2,11,15-17].

Table 1. Means $(\bar{x})$ with standard deviation (SD), coefficients of variation (CV), minimum (Min), and maximum (Max) for the drip loss of chicken breast meat in relation to vertical fiber direction, core diameter (10, 20, and $30 \mathrm{~mm})$, and measurement interval $(24,48,72,96$, and $120 \mathrm{~h})$.

\begin{tabular}{cccccccc}
\hline Core Diameter/Measurement Interval & $\boldsymbol{n}$ & $\overline{\boldsymbol{x}}$ & $\mathrm{SD}$ & $\mathbf{C V}, \boldsymbol{\%}$ & Min & Max \\
\hline \multirow{4}{*}{$10 \mathrm{~mm}$} & $24 \mathrm{~h}$ & 40 & 1.81 & 0.958 & 52.77 & 0.23 & 3.83 \\
& $48 \mathrm{~h}$ & 40 & 2.79 & 1.065 & 38.18 & 0.85 & 5.90 \\
& $72 \mathrm{~h}$ & 40 & 3.77 & 1.358 & 36.04 & 1.60 & 7.72 \\
& $96 \mathrm{~h}$ & 40 & 4.76 & 1.539 & 32.34 & 2.35 & 8.98 \\
& $120 \mathrm{~h}$ & 40 & 5.75 & 1.760 & 30.59 & 3.10 & 11.02 \\
\hline \multirow{3}{*}{$20 \mathrm{~mm}$} & $24 \mathrm{~h}$ & 40 & 1.72 & 1.105 & 64.39 & 0.40 & 4.76 \\
& $48 \mathrm{~h}$ & 40 & 2.70 & 1.176 & 43.52 & 0.90 & 5.45 \\
& $72 \mathrm{~h}$ & 40 & 3.62 & 1.451 & 40.12 & 1.20 & 7.20 \\
& $96 \mathrm{~h}$ & 40 & 4.59 & 1.664 & 36.26 & 1.95 & 8.86 \\
& $120 \mathrm{~h}$ & 40 & 5.58 & 1.752 & 31.39 & 2.71 & 10.24 \\
\hline \multirow{3}{*}{$30 \mathrm{~mm}$} & $24 \mathrm{~h}$ & 40 & 2.87 & 2.336 & 81.45 & 0.00 & 9.04 \\
& $48 \mathrm{~h}$ & 40 & 4.34 & 2.225 & 51.21 & 1.44 & 9.20 \\
& $72 \mathrm{~h}$ & 40 & 5.74 & 2.360 & 41.13 & 1.44 & 11.82 \\
& $96 \mathrm{~h}$ & 40 & 7.38 & 2.253 & 30.51 & 2.88 & 14.09 \\
& $120 \mathrm{~h}$ & 40 & 9.07 & 2.450 & 27.00 & 4.32 & 16.36 \\
\hline
\end{tabular}

Table 2. Means $(\bar{x})$ with standard deviation (SD), coefficients of variation (CV), minimum (Min), and maximum (Max) for the drip loss of chicken breast meat in relation to horizontal fiber direction, core diameter (10, 20, and $30 \mathrm{~mm}$ ), and measurement interval $(24,48,72,96$, and $120 \mathrm{~h}$ ).

\begin{tabular}{cccccccc}
\hline Core Diameter/Measurement Interval & $\boldsymbol{n}$ & $\overline{\boldsymbol{x}}$ & $\mathbf{S D}$ & $\mathbf{C V}, \boldsymbol{\%}$ & Min & Max \\
\hline \multirow{4}{*}{$10 \mathrm{~mm}$} & $24 \mathrm{~h}$ & 40 & 1.34 & 0.596 & 44.49 & 0.39 & 2.89 \\
& $48 \mathrm{~h}$ & 40 & 2.30 & 0.823 & 35.74 & 0.87 & 4.58 \\
& $72 \mathrm{~h}$ & 40 & 3.34 & 1.042 & 31.25 & 1.50 & 6.33 \\
& $96 \mathrm{~h}$ & 40 & 4.28 & 1.207 & 28.18 & 2.20 & 7.68 \\
& $120 \mathrm{~h}$ & 40 & 5.20 & 1.360 & 26.14 & 2.91 & 9.03 \\
\hline \multirow{3}{*}{$20 \mathrm{~mm}$} & $24 \mathrm{~h}$ & 40 & 1.21 & 0.505 & 41.73 & 0.44 & 2.70 \\
& $48 \mathrm{~h}$ & 40 & 2.08 & 0.640 & 30.72 & 1.13 & 3.66 \\
& $72 \mathrm{~h}$ & 40 & 3.11 & 0.827 & 26.60 & 1.61 & 5.33 \\
& $96 \mathrm{~h}$ & 40 & 4.05 & 0.946 & 23.38 & 2.40 & 6.10 \\
& $120 \mathrm{~h}$ & 40 & 4.99 & 1.080 & 21.67 & 3.15 & 7.10 \\
\hline \multirow{3}{*}{$30 \mathrm{~mm}$} & $24 \mathrm{~h}$ & 40 & 1.98 & 1.163 & 58.82 & 0.00 & 5.69 \\
& $48 \mathrm{~h}$ & 40 & 3.41 & 1.381 & 40.55 & 1.33 & 8.13 \\
& $72 \mathrm{~h}$ & 40 & 5.41 & 1.328 & 24.54 & 2.86 & 11.38 \\
& $96 \mathrm{~h}$ & 40 & 7.22 & 1.628 & 22.55 & 4.29 & 13.82 \\
& $120 \mathrm{~h}$ & 40 & 9.12 & 1.828 & 20.04 & 6.43 & 16.26 \\
\hline
\end{tabular}


With pork meat, Correa et al. [15] found lower average drip losses within $24 \mathrm{~h}(3.54 \%)$ than within $48 \mathrm{~h}(4.66 \%)$. With chicken breast meat, Graberec et al. [16] also reported lower average drip losses within $24 \mathrm{~h}(2.38 \%)$ than within $48 \mathrm{~h}(2.74 \%)$. In a study on pork meat, Filho et al. [2] found average drip losses of $3.13 \%$ within $24 \mathrm{~h}$ and $5.19 \%$ within $48 \mathrm{~h}$. With mutton, Kaić et al. [17] reported average drip losses of $0.65 \%$ within $24 \mathrm{~h}$ and $0.93 \%$ within $48 \mathrm{~h}$. With lamb meat, Holman et al. [11] also reported that drip losses increased with the measurement interval $(0.41 \%=24 \mathrm{~h} ; 0.67 \%=48 \mathrm{~h} ; 0.96 \%=72 \mathrm{~h}$; and $1.49 \%=96 \mathrm{~h})$.

\section{Conclusions}

The study indicates that the EZ-DripLoss in chicken breast meat is highly dependent on the area sampled, fiber orientation, and measurement interval. With respect to the sampled core diameters of 10,20, and $30 \mathrm{~mm}$, it could be suggested that samples of $20 \mathrm{~mm}$ are more suitable for EZ-DripLoss evaluation due to their lower drip losses, and greater effectiveness in sampling procedures. Greater drip losses in the samples with vertical fiber orientation suggest that horizontal fiber orientation should be used when chicken breast meat is evaluated using the EZ-DripLoss method. The measurement interval showed a positive linear relationship with drip loss, indicating that longer periods are needed for its stabilization in chicken breast meat and should be reported in studies that use the EZ-DripLoss method. Although the EZ-DripLoss method is considered to be simple and reproducible, it still has not been researched and standardized. Comparisons of the EZ-DripLoss results obtained with different sampling procedures should be performed with great caution.

Author Contributions: Conceptualization, A.K. and Z.J.; methodology, A.K. and A.Ž.; software, K.P.; validation, A.K., Z.J. and N.K.U.; formal analysis, A.Ž.; investigation, A.K., A.Ž. and N.K.U.; resources, Z.J.; data curation, K.P.; writing—original draft preparation, A.K.; writing—review and editing, N.K.U. and A.K.; visualization, K.P. and A.Ž.; supervision, Z.J., A.K. and N.K.U.; project administration, N.K.U. All authors have read and agreed to the published version of the manuscript.

Funding: Publication was financially supported by the ARRS program group P4-0092.

Institutional Review Board Statement: The study was conducted according to the guidelines of the Declaration of Helsinki, and approved by the Ethics Committee of Faculty of Agriculture University of Zagreb (Class: 114-04/20-03/10; Ref. 251-71-29-02/19-20-2, 30-11-2020).

Informed Consent Statement: Not applicable.

Data Availability Statement: The data that support the findings of this study are available from the corresponding author, A.K., upon reasonable request.

Acknowledgments: Authors would like to thank the Department of Animal Nutrition at the Faculty of Agriculture for their organizational support of the research.

Conflicts of Interest: The authors declare no conflict of interest. The funders had no role in the design of the study; in the collection, analyses, or interpretation of data; in the writing of the manuscript, or in the decision to publish the results.

\section{References}

1. Warner, R.D. The eating quality of meat-IV Water-holding capacity and juiciness. In Lawrie's Meat Science, 8th ed.; Toldrá, F., Ed.; Woodhead Publishing: Kidlington, UK, 2017; p. 419.

2. Filho, R.D.A.T.; Cazedey, H.P.; Fontes, P.R.; Ramos, A.D.L.S.; Ramos, E.M. Drip loss assessment by different analytical methods and their relationships with pork quality classification. J. Food Qual. 2017, 2017, 1-8. [CrossRef]

3. Mason, A.; Abdullah, B.; Muradov, M.; Korostynska, O.; Al-Shamma'a, A.; Bjarnadottir, S.G.; Lunde, K.; Alvseike, O. Theoretical basis and application for measuring pork loin drip loss using microwave spectroscopy. Sensors 2016, 16, 182. [CrossRef] [PubMed]

4. Rasmussen, A.J.; Andersson, M. New method for determination of drip loss in pork muscles. In Proceedings of the 42nd International Congress of Meat Science and Technology, Lillehammer, Norway, 1-6 September 1996; pp. 286-287.

5. DMRI (Danish Meat Research Institute). Instruction Manual for EZ-DripLoss. 2018. Available online: www.dti.dk/specialists/ezdriploss-equipment/35497 (accessed on 31 December 2020).

6. Christensen, L.B. Drip loss sampling in porcine m. longissimus dorsi. Meat Sci. 2003, 63, 469-477. [CrossRef] 
7. Otto, G.; Roehe, R.; Looft, H.; Thoelking, L.; Kalm, E. Comparison of different methods for determination of drip loss and their relationships to meat quality and carcass characteristics in pigs. Meat Sci. 2004, 68, 401-409. [CrossRef] [PubMed]

8. Logan, B.G.; Rusell, D.B.; Biffin, T.E.; Hopkins, D.L.; Smith, M.A. Measurement of drip loss in alpaca (Vicugna pacos) meat using different techniques and sample weights. Meat Sci. 2019, 151,1-3. [CrossRef] [PubMed]

9. Otto, G.; Roehe, R.; Looft, H.; Thoelking, L.; Henning, M.; Plastow, F.S.; Kalm, E. Drip loss of case-ready meat and of premium cuts and their associations with earlier measured sample drip loss, meat quality and carcass traits of pigs. Meat Sci. 2006, 72, 680-687. [CrossRef]

10. Kilgannon, A.K.; Holman, B.W.B.; Mawson, A.J.; Campbell, M.; Collins, D.; Hopkins, D.L. Optimising the EZ-Drip method for aged beef drip loss determination. In Proceedings of the 64th International Congress of Meat Science and Technology (ICOMST), Melbourne, Australia, 12-17 August 2018.

11. Holman, B.W.B.; Alvarenga, T.I.R.C.; Hopkins, D.L. The effect of fibre orientation, measurement interval and muscle on lamb meat drip loss values. Meat Sci. 2020, 161, 107959. [CrossRef]

12. Hughes, J.M.; Oiseth, S.K.; Purslow, P.P.; Warner, R.D. A structural approach to understanding the interactions between colour, water-holding capacity and tenderness. Meat Sci. 2014, 98, 520-532. [CrossRef]

13. SAS Institute Inc. $S A S^{\circledR} 9.4$ Statements: Reference; SAS Institute Inc.: Cary, NC, USA, 2004.

14. Den Hertoh-Meischke, M.J.A.; van Laack, R.J.L.M.; Smulders, F.J.M. The water-holding capacity of fresh meat. Vet. Q. 1997, 19, 175-181. [CrossRef] [PubMed]

15. Correa, J.A.; Méthot, S.; Faucitano, L. A modified meat juice container (EZ-DripLoss) procedure for a more reliable assessment of drip loss and related quality changes in pork meat. J. Muscle Foods 2007, 18, 67-77. [CrossRef]

16. Grabarec, I.; Bedeković, D.; Janječić, Z.; Pintar, J.; Kaić, A. The influence of orthophosphoric acid on the physico-chemical properties of meat of commercial chicken hybrids Ross 308. Krmiva 2016, 58, 9-15.

17. Kaić, A.; Kasap, A.; Širić, I.; Mioč, B. Drip loss assessment by EZ and bag methods and their relationship with pH value and color in mutton. Arch. Anim. Breed. 2020, 63, 277-281. [CrossRef] [PubMed] 